\title{
Cycloartane-3,24,25-triol inhibits MRCKa kinase and demonstrates promising anti prostate cancer activity in vitro
}

Henry I C Lowe ${ }^{1,2,3}$, Charah T Watson ${ }^{1,4}$, Simone Badal ${ }^{1,4^{*}}$, Ngeh J Toyang ${ }^{2,3}$ and Joseph Bryant ${ }^{3}$

\begin{abstract}
Background: Given the high occurrence of prostate cancer worldwide and one of the major sources of the discovery of new lead molecules being medicinal plants, this research undertook to investigate the possible anti-cancer activity of two natural cycloartanes; cycloartane-3,24,25-diol (extracted in our lab from Tillandsia recurvata) and cycloartane-3,24,25-triol (purchased). The inhibition of MRCKa kinase has emerged as a potential solution to restoring the tight regulation of normal cellular growth, the loss of which leads to cancer cell formation.

Methods: Kinase inhibition was investigated using competition binding (to the ATP sites) assays which have been previously established and authenticated and cell proliferation was measured using the WST-1 assay.

Results: Cycloartane-3,24,25-triol demonstrated strong selectivity towards the MRCKa kinase with a $\mathrm{Kd}_{50}$ of $0.26 \mu \mathrm{M}$ from a total of 451 kinases investigated. Cycloartane-3,24,25-triol reduced the viability of PC-3 and DU145 cell lines with $I C_{50}$ values of $2.226 \pm 0.28 \mu \mathrm{M}$ and $1.67 \pm 0.18 \mu \mathrm{M}$ respectively.

Conclusions: These results will prove useful in drug discovery as Cycloartane-3,24,25-triol has shown potential for development as an anti-cancer agent against prostate cancer.
\end{abstract}

Keywords: Cycloartane-3,24,25 triol, MRCKa kinase, Kinase inhibition, Rostate cancer, Ball moss

\section{Background}

Prostate cancer is the second most frequently diagnosed cancer and sixth leading cause of cancer death in males, worldwide [1]. The search for new molecules to combat the rising cases of prostate cancer especially those resistant to current chemotherapy calls for urgent action. Medicinal plants have been one of the major sources for the discovery of a number of current clinically used anticancer drugs.

Previous research conducted in our lab demonstrated the promising anti-cancer properties of Tillandsia recurvata L. (Bromeliaceae) commonly called the Jamaican Ball Moss or the Old Man's beard [2]. In an attempt to identify the critical isolate from this plant that is responsible for the observed said bioactivity, this research uncovered the cycloartane, cycloart-23-ene-3,25-diol

\footnotetext{
*Correspondence: simone.badal@uwimona.edu.jm

${ }^{1}$ Bio-Tech R \& D Institute, Kingston, Jamaica

${ }^{4}$ Natural Products Institute, University of the West Indies, Mona, Jamaica

Full list of author information is available at the end of the article
}

(Figure 1) [3]. Further literature research led us to a closely related cycloartane, cycloartane-3,24,25-triol (Figure 1), which had previously been extracted from the Chrysanthemum morifolium plant and was shown to possess promising chemopreventive properties [4].

Essential biological functions such as the provision of a structural frame work and the driving force for cellular motility and division are mediated by the actin cytoskeleton in all eukaryotic cells. A comprehensive overview of the biological processes that regulate the organization of actin is of recent interest to the regime of cancer therapy [5]. Members of the Rho GTPase family such as myotonic dystrophy kinase-related Cdc42-binding kinases $(\mathrm{MRCK} \alpha)$ are key regulators of the actin cytoskeleton and together with multiple target proteins safe guard the tight regulation of normal cell growth and differentiation $[6,7]$. In the event of genomic alterations or carcinogenesis, eukaryotic cells become predispose to rapid and uncontrollable growth as evidenced by the elevated levels of LIMK1 kinase expressed in prostate cancer, a kinase

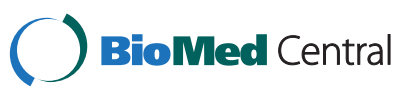



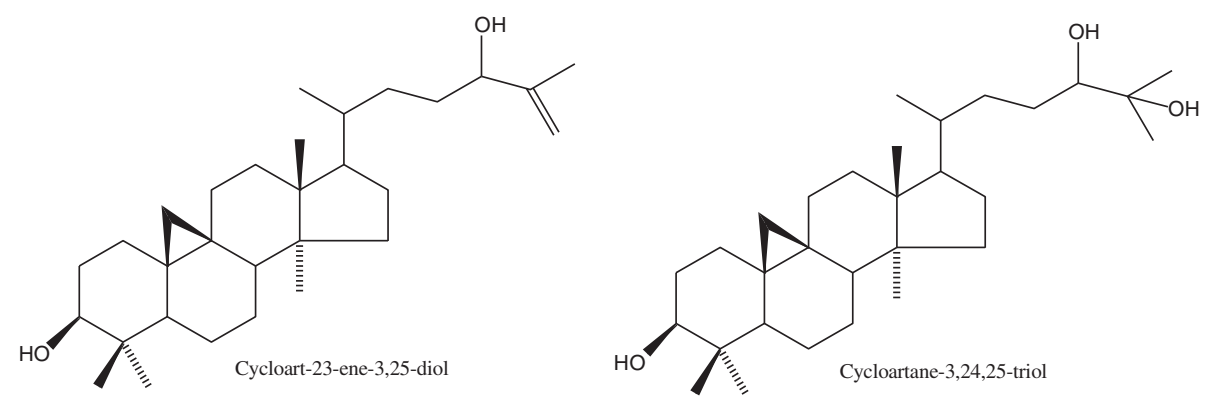

Figure 1 Structures of cycloartanes.

which itself is activated by MRCK $\alpha$ [7]. It is for this reason that inhibitors of these biochemical entities are thought to restore normal cell proliferation and provide a key solution to cancer treatment. The aim of this study therefore was to confirm the promising in vitro anti prostate cancer activity of 2 cycloartane isolates and their effect on prostate cancer related kinases, namely MRCK $\alpha$.

\section{Results and discussion}

GTPases are activated by GTP exchange factors (GEFs) and down-regulated by GTPase-activating proteins (GAPs). Prolonged activation of these molecular entities can initiate a series of signal transduction pathways that can impinge on a number of cellular processes [7]. Amongst the transducers of these signals are protein kinases and increase Rho signalling has been associated with tumour development and/or progression from various origins [8]. The MRCK $\alpha$ kinase, an effector of CDC42 GTPase with functional overlap with ROCK1/2, has also been suggested to have a role in tumour progression [9] and/or invasion [10].

Given the reported elevated levels of MRCK $\alpha$ in cancer tumours relative to normal neighbouring tissues $[9,10]$, the potent selective inhibitory $\left(\mathrm{Kd}_{50}=0.26 \mu \mathrm{M}\right)$ properties of cycloartane-3,24,25-triol towards the MRCK $\alpha$ kinase of a total of 451 kinases tested makes it a promising candidate for further investigation into the treatment of prostate cancer. Not only did this isolate inhibit the MRCK kinase but it also reduced the viability of the PC3 cell line with an $\mathrm{IC}_{50}$ value of $2.226 \pm 0.28 \mu \mathrm{M}$ (Table 1 ). This indicates that cycloartane-3,24,25-triol is more effective than other promising leads towards this cell line as Terracciano et al., [11] investigated an inhibitor of this cell line and only $38 \%$ inhibition was observed at $4 \mu \mathrm{M}$. In addition to reducing the viability of the PC- 3 cell line,

Table 1 IC 50 results of WST-assay for PC-3 and DU145

\begin{tabular}{|c|c|c|}
\hline \multicolumn{2}{|c|}{ Antiproliferation activity $\left(\mathrm{IC}_{50}: \mu \mathrm{M}\right)$} & \multirow{2}{*}{$\frac{\text { Kinase inhibition }\left(\mathrm{Kd}_{50} \mu \mathrm{M}\right)}{\text { MRCKa }}$} \\
\hline PC-3 & Du145 & \\
\hline $2.226 \pm 0.28$ & $1.67 \pm 0.18$ & 0.26 \\
\hline
\end{tabular}

cycloartane-3,24,25-triol also reduced the viability of another prostate cancer cell line DU145 with an $\mathrm{IC}_{50}$ value of $1.67 \pm 0.18 \mu \mathrm{M}$ (Table 1 ). This observed bioactivity makes this isolate even more relevant in prostate cancer treatment than omega-3FAs; docosaheenois acid (DHA) and eicosapentaenoic acid (EPA) that both reduced the viability of $\mathrm{PC}-3$ cell line comparable to cycloartane-3,24,25-triol but showed no impact towards DU145 cells [12].

\section{Conclusions}

We report for the first time this inhibition of MRCK $\alpha$ kinase inhibition by cycloartane-3,24,25-triol. Of the 451 kinases, cycloartane-3,24,25-triol selectively inhibited MRCK $\alpha$ with greater potency than other potential chemotherapeutics. Our findings show that the bioactivity of this isolate not only inhibits MRCK $\alpha$ known to be associated with prostate cancer, but also reduced the viability of two prostate cancer cell lines, PC-3 and DU145 implicating the validity of these results in anti-cancer drug discovery.

\section{Material and methods \\ Chemicals}

The Cayman's WTS-1assay kit which was used for the cell proliferation assay and kinase inhibition assay chemicals were purchased from Cayman Chemical Company.

\section{Cell lines and culture medium}

All cell lines with their respective media and supplements were obtained from ATCC (Manassas, VA, USA).

\section{Cell proliferation}

The cells (PC-3 and DU145) were maintained in minimum essential media (MEM) supplemented with $10 \%$ foetal calf serum (FCS), $20 \mathrm{mMl}$-glutamine, $2 \%$ penicillinstreptomycin, and $0.2 \%$ gentamicin. Cells were maintained at $37^{\circ} \mathrm{C}$ with $5 \% \mathrm{CO}_{2}$ in Corning $75 \mathrm{~cm}^{3}$ culture flasks. Cells were trypsinized and plated at the appropriate density (500-2000 cells/well in log phase $72 \mathrm{~h}$ post drug addition) into 96 well plates in media for approximately 

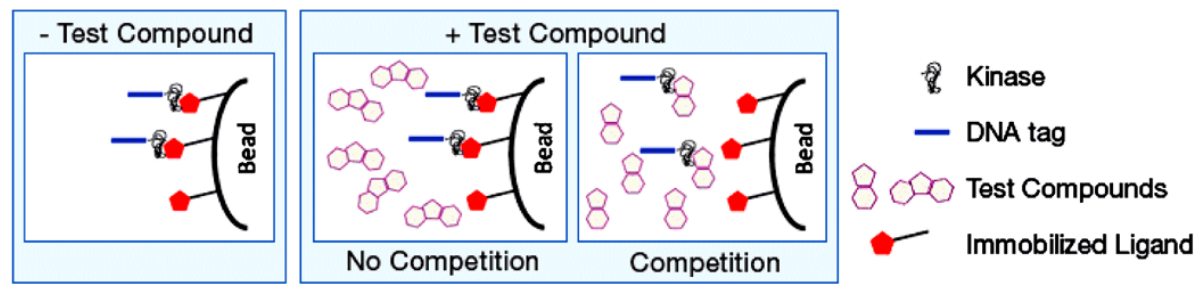

Figure 2 How the KinomeScan assay works (Courtesy of DiscoveRx).

$18 \mathrm{~h}$ after which they were exposed to cycloartanes; cycloart-23-ene-3,25-diol and cycloartane, cycloart-23-ene3,25-triol for $72 \mathrm{~h}$. The compounds were solubilized in DMSO ( $>0.1 \%)$. Following the appropriate treatments, cell proliferation was measured using the WST-1 (4-[3-(4-iodophenyl)-2-(4-nitrophenyl)-2H-5-tetrazolio]-1, 3-benzene disulfonate) (Roche) colorimetric assay according to the manufacturer's instructions [13]. All assays were performed in duplicates and were monitored spectrophotometrically at $450 \mathrm{~nm} / 690 \mathrm{~nm}$ (Synergy HT 96-well Plate Reader - BIO-TEK). Cell viability was assessed as percent of drugs relative to vehicle solvent-treated control. $\mathrm{IC}_{50}$ values were determined from the extract dose versus control growth curves using Graph Prism software.

\section{Kinase inhibition assay}

Competition binding assays were established, authenticated and executed as described previously [14,15]. For most assays, kinases were fused to T7 phage strains [14] and for the other assays, kinases were produced in HEK-293 cells after which they were tagged with DNA for quantitative PCR detection (data not shown). In general, full-length constructs were used for small, single domain kinases, and catalytic domain constructs for large multi-domain kinases. The binding assays utilized streptavidin-coated magnetic beads treated with biotinylated small molecule ligands for 30 minutes at room temperature which generated affinity resins for the kinase assays. The liganded beads were blocked with excess biotin and washed with blocking buffer (SeaBlock (Pierce), $1 \%$ BSA, $0.05 \%$ Tween 20, $1 \mathrm{mM}$ DTT) to remove unbound ligand and to reduce non-specific phage binding. Binding reactions were assembled by combining kinases, liganded affinity beads, and test compounds in $1 \mathrm{x}$ binding buffer (20\% SeaBlock, 0.17x PBS, 0.05\% Tween 20, $6 \mathrm{mM}$ DTT). Test compounds were prepared as $40 \mathrm{x}$ stocks in $100 \%$ DMSO and diluted directly into the assay (Final DMSO concentration $=2.5 \%$ ). All reactions were performed in polypropylene 384- well plates in a final volume of $0.04 \mathrm{ml}$. The assay plates were incubated at room temperature with shaking for 1 hour and the affinity beads were washed with wash buffer ( $1 \mathrm{x}$ PBS, $0.05 \%$ Tween 20). The beads were then re-suspended in elution buffer (1× PBS, 0.05\% Tween 20, $0.5 \mu \mathrm{M}$ non-biotinylated affinity ligand) and incubated at room temperature with shaking for 30 minutes. The kinase concentration in the eluates was measured by quantitative PCR and Table 1 presents $\mathrm{kd}_{50}$ for kinase interaction with the test compound. These were determined using a standard dose response curve using the hill equation. Curves were fitted using a non-linear least square fit with the LevenbergMarquardt algorithm. Figure 2 illustrates the kinase interaction process.

\section{Plant material: Tillandsia recurvata (extraction and isolation)}

The whole $T$. recurvata plant was collected from trees and electricity poles at Kingston, Jamaica. A voucher specimen of the plant was identified at the Institute of Jamaica Herbarium where it is deposited with Accession Number: IJ 3411. The collected plant material was air dried, pulverized into powder. $2.3 \mathrm{~kg}$ of Ball Moss biomass was extracted twice with $5 \mathrm{~L}$ of Chloroform. The filtrate was dried in a rotavapor to obtain a dark green residue (87.6 g).

\section{Competing interest}

The authors declare no competing interest at this time.

\section{Authors' contribution}

Conceived and designed the experiments: $\mathrm{HL}$ and JB, Acquisition of data: CW and NT, Analyzed and interpreted the data: NT and SB. Wrote the paper: SB and NT, Critical and intellectual revision of the article contents: SB and NT. All authors read and approved the final manuscript.

\section{Authors' information}

Dr. Henry Lowe is a specialist in medicinal chemistry with approximately 50 years of experience in the field, he currently holds a PhD from the Manchester University, a M,Sc. from the University of Sydney and B.Sc. (hons) from UCWI, London University. He holds several postdoctoral studies including but not limited from; Harvard University and M.IT, USA. Dr. Simone Badal is currently a post-doctoral fellow at the Natural Products Institute, UWI, Mona where she recently completed her PhD (Biochemistry) in cancer research and holds a B.Sc. (hons) and M.Phil. in Biochemistry from the University of the West Indies, Mona. She also obtained her MBA in International Relations from the University of Wales, Cardiff. Ms. Charah Watson is a PhD candidate specialising in Natural products chemistry in the Department of Chemistry at the UWI, Mona. Her research activities include natural product isolation, elucidation and identification and their use as natural pest control and anti-cancer agents. Mr. Ngeh Toyang is a PhD candidate in Pharmacognosy with the Division of Pharmacognosy, Leiden University where his research focus is on cancer and HIV/AIDS. Dr. Joseph Bryant holds a Doctor of Veterinary Medicine degree from Tuskegee University specialising in cancer and HIV/AIDS research. A board certified 


\section{Acknowledgement}

The authors are grateful to Dr. Rena Lapidus of the Translational Core of the Greenebaum Cancer Center, University of Maryland School of Medicine for validating the results of the anticancer activity of Cycloartane-3,24,25-triol and to the KINOMEscan group (San Diego) for carrying out the kinase inhibition assays.

\section{Author details}

'Bio-Tech R \& D Institute, Kingston, Jamaica. ${ }^{2}$ Educational and Scientific Corporation, Florida, USA. ${ }^{3}$ Institute of Human Virology, University of Maryland School of Medicine, Baltimore, MD, USA. ${ }^{4}$ Natural Products Institute, University of the West Indies, Mona, Jamaica.

Received: 3 August 2012 Accepted: 10 November 2012 Published: 14 November 2012

\section{References}

1. Jemal A, Bray F, Center M, Jacques Ferlay M, Ward E, Forman D: Global cancer statistics. CA Cancer J Clin 2011, 61:69-90.

2. Lowe H: In Anti-Tumor and Anti-Inflammatory Extracts of Plant Biomass and Their Uses. Edited by Patent US. Jamaica; 2010:1-14. US 7,713,556 B2.

3. Cabrera GM, Seldes AM: Hydroperoxycycloartanes from Til landsia recurvata. J Nat Prod 1995, 58:1920-1924.

4. Kikuchi T, Akihisa T, Tokuda H, Ukiya M, Watanabe K, Nishino H: Cancer chemopreventive effects of cycloartane-type and related triterpenoids in in vitro and in vivo models. J Nat Prod 2007, 70:918-922.

5. Hall A: Rho GTPases and the actin cytoskeleton. Science 1998, 23:509-514.

6. Heikkila T, Wheatley E, Crghton D, Schroder E, Boakes A, Kaye S, Mezna M, Pang L, Rushbrooke M, Turnbull A, et al: Co-crystal structures of inhibitors with MRCK $\beta$, a key regulator of tumor cell invasion. PloSOne 2011, 6:1-12.

7. Jaffe A, Hall A: RHO GTPASES: biochemistry and biology. Annu Rev Cell Dev Bi 2005, 21:247-269.

8. Sahai E, Marshall CJ: ROCK and Dia have opposing effects on adherens junctions downstream of Rho. Nat Cell Biol 2002, 4:408-412.

9. Benitaha SA, Valeróna PF, Aelstb L, Marshallc CJ, Lacala JC: Rho GTPases in human cancer: an unresolved link to upstream and downstream transcriptional regulation. Biochimica et Biophysica Acta 2005, 1705:121-132.

10. Wilkinson S, Paterson HF, Marshall CJ: Cdc42-MRCK and Rho-ROCK signalling cooperate in myosin phosphorylation and cell invasion. Nat Cell Biol 2005, 7:255-261.

11. Terracciano D, Mazzarella C, Di Carlo A, Mariano A, Ferro M, Di Lorenzo G, Giordano A, Altieri V, De Placido S, Macchia V: Effects of the ErbB1/ErbB2 kinase inhibitor GW2974 on androgen-independent prostate cancer PC-3 cell line growth and NSE, chromogranin A and osteopontin content. Oncol Rep 2010 2010, 24:213-217.

12. Rose D, Connolly J: Effects of fatty acids and eicosanoid synthesis inhibitors on the growth of two human prostate cancer cell lines. The Prostate 1991, 18:243-254.

13. Ngamwongsatit P, Banada PP, Panbangred W, Bhunia AK: WST-1-based cell cytotoxicity assay as a substitute for MTT-based assay for rapid detection of toxigenic Bacillus species using CHO cell line. J Microbiol Meth 2008, 73:211-215.

14. Fabian MA, Biggs WH III, Treiber DK, Atteridge CE, Azimioara MD, Benedetti MG, Carter TA, Ciceri P, Edeen PT, Floyd M, et al: A small molecule-kinase interaction map for clinical kinase inhibitors. Nat Biotechnol 2005, 23:329-336.

15. Karaman MW, Herrgard S, Treiber DK, Gallant P, Atteridge CE, Campbell BT, Chan KW, Ciceri P, Davis MI, Edeen PT, et al: A quantitative analysis of kinase inhibitor selectivity. Nat Biotechnol 2008, 26:127-132.

\section{doi:10.1186/1475-2867-12-46}

Cite this article as: Lowe et al: Cycloartane-3,24,25-triol inhibits MRCKa

kinase and demonstrates promising anti prostate cancer activity in vitro. Cancer Cell International 2012 12:46. 